ARTIGO

\title{
O trabalho educativo entre metas e produtividade: o acordo de resultados em Minas Gerais
}

Abelardo Bento Araújo a

\section{Resumo}

Neste artigo, analisa-se a contratualização de resultados na educação, que submete o trabalho educativo a determinado conceito de produtividade, impondo metas para a aferição dessa produtividade. A pesquisa qualitativa foi realizada em escola pública da rede estadual, com 15 profissionais, entre professores, coordenadores pedagógicos e diretor escolar. A discussão se pauta em dois conceitos fundamentais: o de trabalho educativo e o de produtividade do trabalho educativo, ambos decorrentes da concepção de educação como apropriação da cultura, processo de formação do humano-histórico. Assim, revela-se o Acordo de Resultados como política que atravessa o Sistema Mineiro de Avaliação e Equidade da Educação Pública (Simave), mudando o modo como se compreende a produtividade da escola, ditando formas de controle do trabalho educativo e conformando práticas curriculares.

Palavras-chave: Qualidade da educação. Avaliação. Acordo de resultados.

\section{Introdução}

A escola é apressada, demasiado apressada. É verdade que ela é ciosamente vigiada por contramestres que, tal como na indústria, exigem normas de produção e certa regularidade do esforço. É um pouco como um engenheiro que quisesse medir a metro o seu consumo de eletricidade - tarefa vã. Então, na falta dessa medição do enriquecimento humano, a escola vai limitar-se à medição da aquisição, como se mede um vaso que se enche... Mas até essa aquisição escaparia muitas vezes ao vosso controle desconfiado se vocês não tivessem as palavras que são os sinais e a expressão dela (FREINET, 1974, p. 166).

\footnotetext{
a Centro Federal de Educação Tecnológica de Minas Gerais - CEFET-MG. Belo Horizonte, MG, Brasil.
} 
No trecho citado como epígrafe, retirado da obra A educação do trabalho, Celestin Freinet, permite perceber a imposição da medição na escola "como se mede um vaso que se enche" (FREINET, 1974, p. 166), na falta da medição do enriquecimento humano. O ponto de partida desse texto é o enriquecimento humano, que nada mais é do que a apropriação da cultura, como objetivo da educação. Educação é o processo por meio do qual o ser humano torna-se humano-histórico, ao apropriar-se daquilo que foi produzido pela própria humanidade, em sucessivas gerações: a linguagem, os valores, a arte, em suma, a cultura.

A análise proposta neste texto ${ }^{1}$, além de se ancorar nessa concepção de educação como apropriação da cultura (LEONTIEV, 2004; PARO, 2010), tem como base um conceito decorrente, de trabalho educativo. Se a educação é o processo por meio do qual o ser humano se humaniza, em sentido histórico, e o trabalho é, como define Marx (1996, p. 298), "atividade orientada a um fim", o trabalho educativo se constitui na atividade intencionalmente estruturada para propiciar as condições de apropriação da cultura, aqui também pensada amplamente, segundo Freire (1987), como produto da ação humana.

Compreende-se que, na exposição da elevação de escores de rendimento dos alunos das escolas mineiras em testes, o Estado assume a produtividade da escola sob a redução desta "à relação entre gastos com o ensino e o montante de promovidos, ou aprovados em testes" (PARO, 2003, p. 14). Ao contrário, neste artigo a produtividade é tomada como "faculdade de realizar um produto", que, no caso da escola, não se resume a aprovação em testes ou vestibulares nem à preparação para o mercado de trabalho, mas abarca o "próprio resultado da apropriação do saber em seu sentido mais amplo, capaz de concorrer para a constituição do educando como cidadão e sujeito histórico" (PARO, 2003, p. 14).

Tomada com significado alheio aos objetivos educacionais, a ideia de produtividade do trabalho se assenta sobre a suposta objetividade dos sistemas de avaliação utilizados para aferir um produto do trabalho educativo. $\mathrm{O}$ acirramento dessa concepção imprime a ideia de que os resultados de testes são o verdadeiro produto do trabalho do professor, esquecendo-se de que quem entra na atividade educativa como objeto de trabalho ${ }^{2}$ (apenas em termos analíticos, uma vez que é sujeito), a fim de transformar-se, e que também será o produto dessa atividade é o aluno,

\footnotetext{
O texto é parte da tese intitulada "Avaliação e controle do trabalho educativo: contradições entre meios e fins no monitoramento da qualidade da educação", defendida em 2016, na Faculdade de Educação da Universidade de São Paulo (USP), sob a orientação do Professor Vitor Henrique Paro.

2 No âmbito da Economia Política, Marx (1996) afirma que o objeto de trabalho é aquilo que sofre a transformação durante o processo de trabalho, para dar origem ao produto do trabalho.
} 
embora, como trabalho e atividade política que é, a educação também transforme o professor. Esquece-se, ainda, de que a avaliação desse "produto" não pode dar-se completa e definitivamente no momento de realização do processo. Como afirma Paro (2012), os resultados da educação do ser humano tornam-se mais expressivos em sua convivência em sociedade. Por isso, a avaliação realizada durante o processo educativo escolar tem um fim mediador - de possibilitar a reorientação desse próprio processo educativo; e não de aferir um produto pronto, como na produção de objetos.

Este artigo coloca em relevo questões decorrentes do Acordo de Resultados, que condensa a contratualização de resultados, submetendo o trabalho educativo a um conceito reduzido de produtividade ao centrar seus objetivos em metas quantitativas. Contribui-se, assim, para preencher a lacuna apontada por Minhoto e Penna (2011, p. 161). Segundo as autoras, na associação da elevação da qualidade da educação ao pagamento de prêmios, "a questão central subjacente à qualidade da docência fica intocada, qual seja: a natureza complexa do trabalho do professor (e da escola)". Para tal, discute-se a visão dos professores sobre a vinculação, na política educacional mineira, de metas ao prêmio de produtividade. Apresenta-se o Acordo de Resultados, considerando o contrato do ano de 2013. Em seguida, discute-se, com base nas falas dos profissionais da educação pesquisados a relação entre as metas e a produtividade da escola. Nas considerações finais, retomase a discussão sobre o produto da educação, apontando possíveis impactos da avaliação e da quantificação das metas ancoradas em escores de rendimento de alunos em testes em larga escala.

\section{O acordo de resultados}

Num contexto mundial de políticas de avaliação, o Brasil faz uso inclusive de um indicador internacional, o Program for International Student Assessment (PISA), desenvolvido pela Organização de Cooperação e de Desenvolvimento Econômico (OCDE), além do indicador nacional, o Índice de Desenvolvimento da Educação Básica (Ideb). No âmbito local, o Acordo de Resultados sintetiza a contratualização de resultados entre o governo estadual de Minas Gerais e as escolas. O Acordo faz parte do Plano Plurianual de Ação Governamental $(\mathrm{PPAG})^{3}$, conforme o Plano Mineiro de Desenvolvimento Integrado (PMDI) ${ }^{4}$.

\footnotetext{
3 O Plano Plurianual de Ação Governamental (PPAG) normatiza o planejamento da administração pública de médio prazo. De acordo com a Secretaria de Planejamento e Gestão de Minas Gerais, é a referência para a formulação dos programas governamentais quadrienais, seguindo as leis e diretrizes orçamentárias do estado.

4 O Plano Mineiro de Desenvolvimento Integrado (PMDI) estabelece as principais diretrizes para a atuação do governo estadual até o ano de 2030. Tem como principal objetivo possibilitar a relação entre as políticas setoriais.
} 
Nesse acordo, os pactuantes fixam metas de resultados com diferentes tipos de cálculo por área.

$\mathrm{Na}$ educação, o foco são os escores de desempenho nas avaliações externas. Além das avaliações estaduais, esses resultados consideram também o Ideb da escola. As escolas assumem as metas pactuadas e o Governo de Minas Gerais assume o compromisso de pagar o prêmio de produtividade anualmente, com base nessas metas e na avaliação de desempenho do servidor público do Estado. O Ofício Circular no 2/2013, de 19 de julho de 2013 (MINAS GERAIS, 2013a), da Assessoria de Gestão Estratégica e Inovação (AGEI) da Secretaria Estadual de Educação de Minas Gerais (SEE/MG), instrui os diretores sobre os passos a serem seguidos para a realização do pacto do Plano de Metas e alerta que as escolas que deixarem de assinar e entregar o Plano serão desligadas do Acordo e não receberão o prêmio de produtividade. O documento informa que as metas são factíveis, porque elaboradas de acordo com a série histórica das escolas.

O Acordo de Resultados está ligado ao Sistema Mineiro de Avaliação e Equidade da Educação Pública (Simave) ${ }^{5}$, criado em 2000 e composto por três programas de avaliação. O Programa de Avaliação da Alfabetização (Proalfa) faz parte do Simave desde 2006, e avalia os alunos do $3^{\circ}$ ano do Ensino Fundamental em Língua Portuguesa. O Programa de Avaliação da Rede Pública de Educação Básica (Proeb) é o principal programa que coloca o Simave em prática: avalia anualmente alunos do Ensino Fundamental matriculados no $5^{\circ}$ e no $9^{\circ}$ anos, além de alunos do $3^{\circ}$ ano do Ensino Médio das redes públicas estadual e municipal. O foco das avaliações são as disciplinas de Língua Portuguesa e Matemática. Em 2000, foram aplicados os testes de Língua Portuguesa e Matemática. Em 2001, de História, Geografia e Ciências. No entanto, após completar o ciclo de Língua Portuguesa em 2002 e o de Matemática em 2003, a SEE/MG resolveu concentrar os testes em Língua Portuguesa e Matemática, diante dos resultados. O terceiro é o Programa de Avaliação da Aprendizagem Escolar (PAAE), por meio do qual a SEE/MG disponibiliza um banco de questões, criando uma correspondência entre avaliações internas, realização de diagnósticos e o que se afere nas avaliações externas (INSTITUTO AVALIAR, 2015). As questões são elaboradas com base no Conteúdo Básico Comum (CBC), documento da SEE/MG que orienta os currículos de educação básica no Estado. Segundo o Instituto Avaliar, que realiza o PAAE, o Programa possibilitaria intervenções pedagógicas personalizadas.

5 A nomenclatura do Simave foi alterada em 2016, com a inserção da palavra "equidade". 
O Acordo de Resultados evidencia ainda mais a concepção que orienta os Programas de avaliação do Simave. O Acordo vincula ao prêmio de produtividade dos servidores públicos do Estado de Minas Gerais, além da avaliação de desempenho do servidor público, os resultados das avaliações em larga escala, por meio de metas acordadas entre a escola e a SEE/MG. As escolas podem apresentar contrapropostas às metas indicadas pela SEE/MG, mas, como se constata a seguir, em pesquisa realizada pela Universidade Federal de Minas Gerais - UFMG (UFMG, 2011), as contrapropostas nem sempre são aceitas, especialmente com solicitações de redução das metas.

Criado no âmbito do Choque de Gestão e materialização das estratégias da Nova Gestão Pública em Minas Gerais, inscrita no gerencialismo, o Acordo de Resultados teve seus objetivos redefinidos em 2008, pela Lei Estadual $n^{\circ} 17.600$, de $1^{\circ}$ de julho de 2008 (MINAS GERAIS, 2008). O Decreto Estadual no 46.170, de 27 de fevereiro de 2013 (MINAS GERAIS, 2013b), que disciplina o pagamento do prêmio de produtividade, estabelece os prazos para definição do montante do prêmio, pago anualmente, de acordo com as definições do instrumento da pactuação da segunda etapa do Acordo, também editado anualmente. O Decreto estabelece, ainda, os critérios da avaliação satisfatória.

O primeiro Acordo de Resultados entre a SEE/MG e as escolas estaduais ocorreu em 2007. Essa contratualização de resultados é feita em duas etapas. A primeira define metas gerais e é assinada entre o Governador do Estado e a SEE/MG. A segunda é assinada entre a SEE/MG e os setores a ela relacionados, entre esses, as escolas. Para as escolas, apesar de haver outros indicadores, a maior parte das metas se refere aos escores de desempenho nas avaliações externas (Quadro 1). $\mathrm{O}$ alcance das metas da segunda etapa serve à estratégia do prêmio de produtividade, que, dependendo da porcentagem das metas atingidas, pode corresponder a um "décimo quarto salário", pago no ano subsequente àquele ao qual as metas se referem. Além das metas, considera-se a avaliação de desempenho individual, levando em conta, por exemplo, o número de dias trabalhados.

O Acordo de Resultados passou por várias redefinições, desde 2003. Neste texto, optou-se pela exposição do Acordo tal como está presente nos documentos do Plano de Metas 2013-2014. O Quadro 1 resume os indicadores da primeira etapa do Acordo.

Com o objetivo de destacar a perspectiva de quantificação que esse Acordo aplica ao trabalho educativo, reproduz-se o Quadro 2 com as metas da segunda etapa 
Quadro 1. Resumo dos indicadores da primeira etapa do Acordo de Resultados.

\begin{tabular}{|c|c|}
\hline Objeto de pactuação* & Indicadores \\
\hline \multirow{4}{*}{ 1. Indicadores Finalísticos } & $\begin{array}{l}\text { Indicador 1: Percentual de alunos do } 3^{\circ} \text { ano do Ensino } \\
\text { Fundamental no nível recomendável de leitura } \\
\text { (rede estadual) - Proalfa }\end{array}$ \\
\hline & $\begin{array}{l}\text { Indicador 2: Ideb anos iniciais do Ensino Fundamental } \\
\text { (rede estadual) }\end{array}$ \\
\hline & $\begin{array}{l}\text { Indicador 3: Ideb anos finais do Ensino Fundamental } \\
\text { (rede estadual). }\end{array}$ \\
\hline & Indicador 4: Ideb do Ensino Médio (rede estadual) \\
\hline 2. Entregas Estratégicas & - \\
\hline \multirow{3}{*}{ 3. Qualidade do Gasto } & $\begin{array}{l}\text { Indicador 1: Índice de Execução do Planejamento Anual de } \\
\text { Compras }\end{array}$ \\
\hline & Indicador 2: Índice de Ociosidade de Materiais Estocados \\
\hline & Indicador 3: Índice de Regionalização da Execução \\
\hline
\end{tabular}

* No objeto de pactuação "entregas estratégicas" incluem-se projetos estratégicos da SEE/MG em regiões específicas do Estado. As entregas estratégicas se referem aos acordos específicos desses projetos.

Fonte: Adaptado de Minas Gerais (2013c).

do Acordo, previstas para as escolas estaduais de Minas Gerais. Nesse quadro, verifica-se o peso dos escores dos testes externos na avaliação do trabalho educativo.

O modelo de gestão do Acordo de Resultados prioriza o controle dos resultados em detrimento da avaliação dos processos. Para isso, traduz objetivos em indicadores de resultados e os torna parte de metas mais amplas. Como consequência, o acordo confere aos setores pactuantes autonomia na gestão de recursos e, em caso de desempenho satisfatório, o pagamento do prêmio de produtividade. As escolas são entendidas como meras unidades executoras de uma atividade técnica - e aqui se esquece completamente de que o caráter técnico da atividade educativa é precisamente ela ser uma atividade política, por ser realizada por meio de uma relação entre sujeitos (PARO, 2011; 2015).

Como se verifica no Quadro 2, apenas três dos indicadores não se referem à proficiência aferida pelas avaliações externas (Nota da SRE na $2^{\text {a }}$ Etapa do Acordo de Resultados; Taxa de distorção idade-série no ensino fundamental e Taxa de distorção idade-série no ensino médio). A política diz tratar-se de um acordo. No entanto, o relatório da pesquisa Avaliação externa como instrumento da gestão educacional nos estados, realizada pelo Grupo de Avaliação e Medidas Educacionais (Game) da UFMG aponta, nas falas de entrevistados, divergências quanto a essa característica: "Acontece esse tipo de coisa por quê? Porque se 


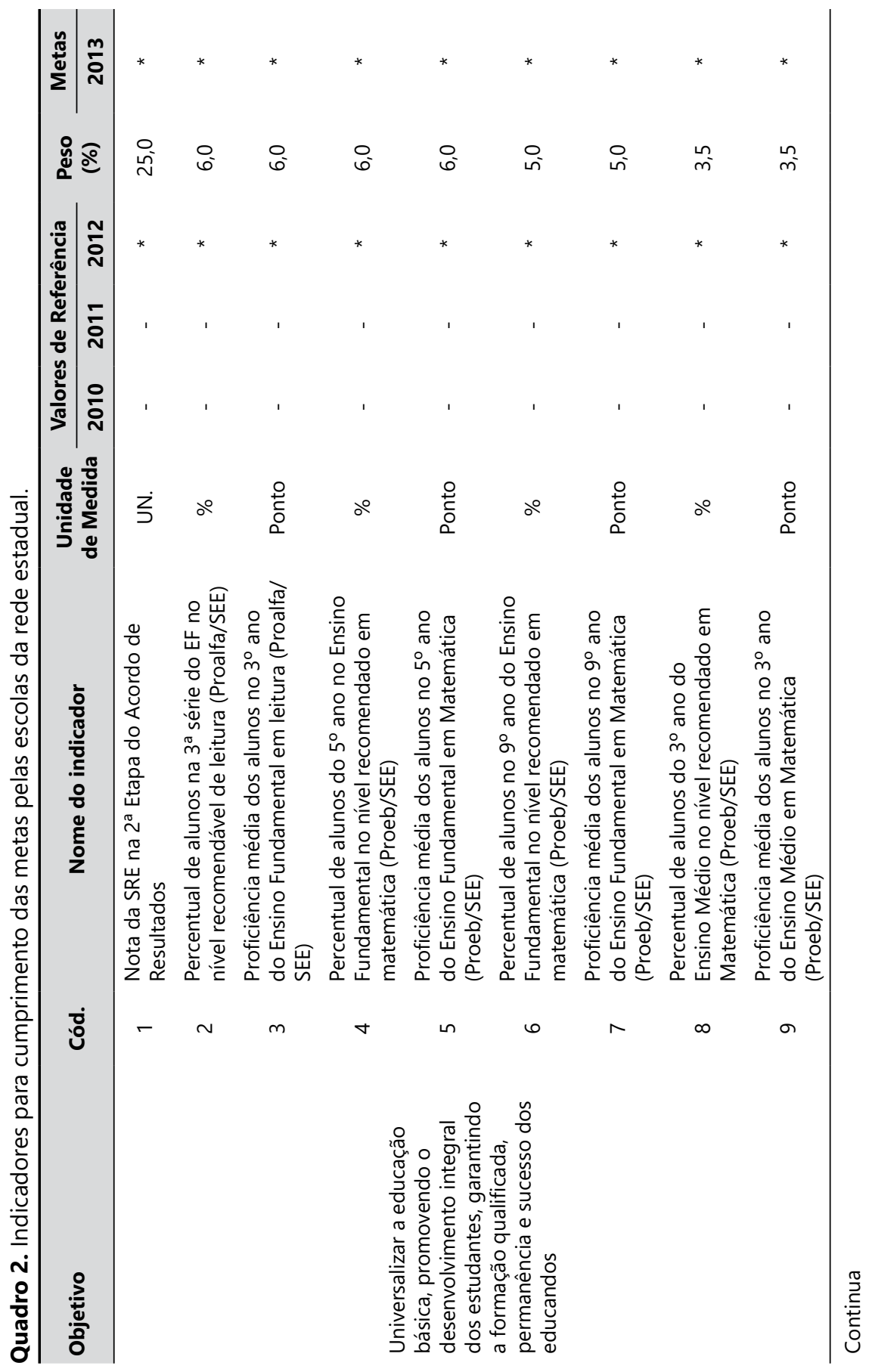




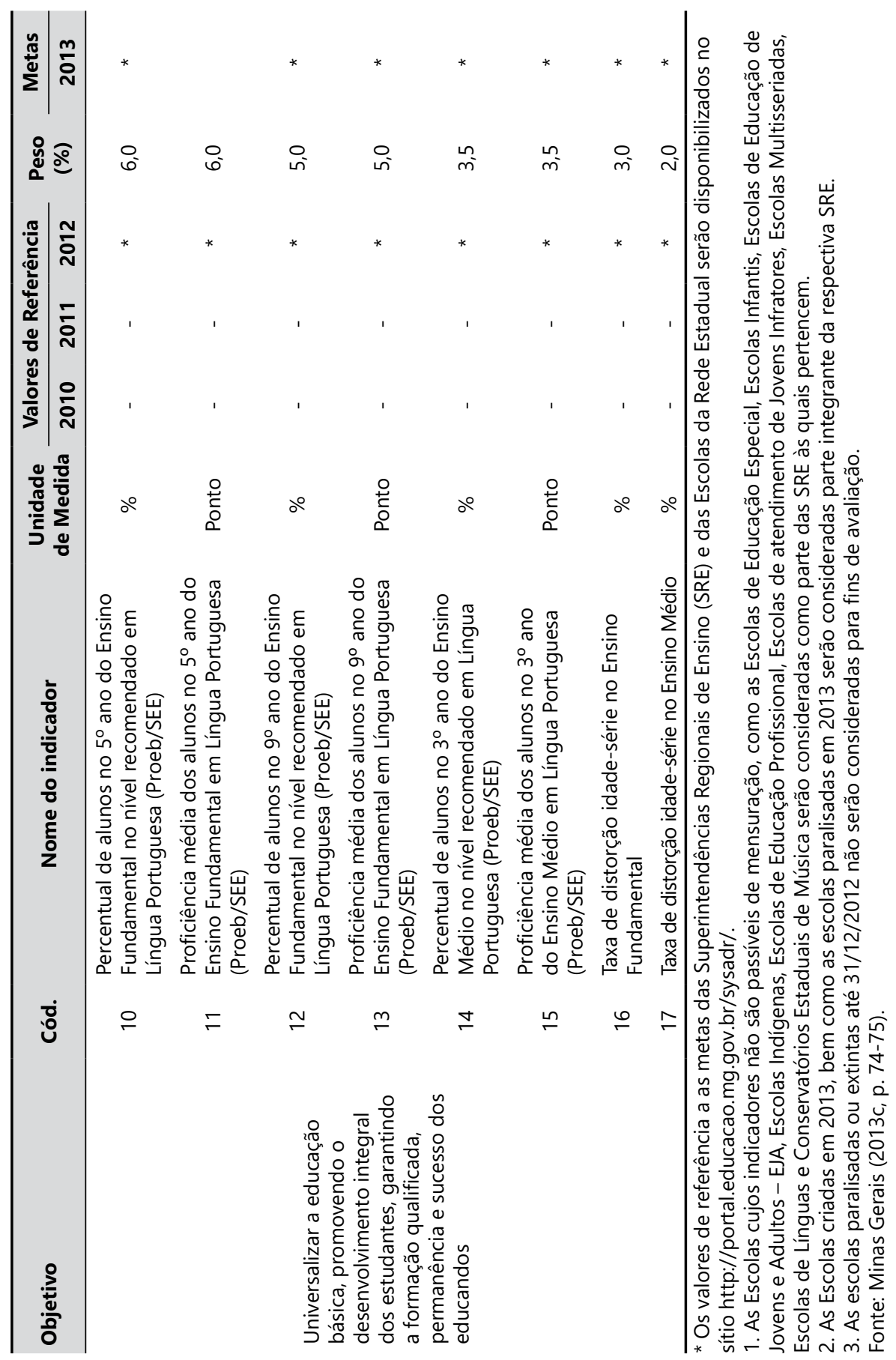


eu não conseguir, eu vou perder salário e ninguém está em condições de perder salário" - Gestor: SEE/MG (UFMG, 2011, p. 154-155). As metas são propostas pela SEE/MG, podendo as escolas realizar contrapropostas. Ao final, assina-se um acordo confirmando-as. Apesar dessa afirmação da SEE/MG, um técnico da própria Secretaria nega a aparente perspectiva democrática: "[em 2009], de 3.988 escolas foram de $10 \%$ os pedidos de alteração [...]. E, desses $10 \%$, nós modificamos só $10 \%$, o resto não. Na verdade assim, vinha muito pedido de abaixar meta" - Técnico: SEE/MG (UFMG, 2011, p. 155). O relatório destaca que as metas de aumento dos escores correspondem à meta geral estabelecida para o Estado e que "nem sempre os planejadores ouvem os gestores antes de fixar as metas globais do Estado [sic]" (UFMG, 2011, p. 156). Em 2010, ao avaliar as metas estabelecidas na gestão anterior, por considerar muito altas, a própria SEE/MG resolveu revisá-las, com base nas médias de avanços registrados nos anos anteriores, mas isso não significou maior participação das escolas.

Em 2015, o Governo de Minas Gerais não pagou o prêmio de produtividade, mas esse prêmio não foi extinto oficialmente. O Secretário de Planejamento e Gestão do Governo de Fernando Pimentel (PT-MG) reconheceu dever aos profissionais da educação esse prêmio, mas disse que o governo não tinha condições de pagar (DINIZ, 2015). Logo, o pagamento do prêmio deixou de ser realizado não por rupturas com o modelo político anterior, mas por falta de condições financeiras.

\section{Metas e prêmio de produtividade na política educacional de Minas Gerais}

Neste tópico, analisam-se as falas dos profissionais da educação pesquisados a respeito do sistema de premiação com base em metas e produtividade. Apesar das peculiaridades em cada um dos posicionamentos, nenhum dos entrevistados concorda com a forma como as avaliações são realizadas e utilizadas na política educacional mineira. Foram adotados nomes fictícios para preservar a identidade dos sujeitos que participaram da pesquisa.

Um dos professores de História, João, acha problemática a relação entre o prêmio de produtividade e os resultados de avaliações externas. "[...] quanto mais direta, mais problemática fica, porque não leva em consideração todos os contextos em que a escola está inserida". O professor enumera os pormenores do contexto em que se insere a escola, mencionando conflitos em comunidades próximas: "Então, isso acaba interferindo." A fala do professor João vai ao encontro da fala da professora Sandra, que leciona para o segundo ano do ensino fundamental, a respeito das condições concretas de vida dos alunos 
como fatores que interferem na aprendizagem. João demonstra entender que o conjunto de disposições para estudar é culturalmente apropriado pela criança nos contatos com o grupo em que ela se desenvolve e na própria escola. Segundo ele, a ausência de algumas condições tem impacto naquilo que se considera como resultado: "Então, muitas vezes, a própria necessidade de disciplina que uma pessoa precisa ter para fazer uma prova, para fazer uma atividade, esses alunos não têm. Eles não trazem isso. Antes de fazer uma prova, você precisa ensinar o aluno a sentar-se e se concentrar."

Além das questões ligadas aos alunos, especificamente, o professor se refere às diferenças entre as escolas e suas condições de trabalho. Segundo ele, interfere na aprendizagem do aluno o próprio ritmo de trabalho da escola: "Muitos professores são designados. Então, termina o contrato, muda o professor. Às vezes, há período de licenças. Todos esses movimentos acabam gerando problema de descontinuidade do processo de aprendizagem". O professor ainda coloca em questão o teste como instrumento de avaliação direta do aluno e de avaliação indireta do professor como servidor público:

Então, quando se vai avaliar a aprendizagem de um aluno, avaliá-la apenas baseado numa prova, por mais que isso seja legítimo que aconteça, não pode ser o único critério para a avaliação de desempenho de um servidor. Porque outros fatores teriam que ser ponderados para poder avaliar isso com mais precisão (João Professor de História).

Além daquelas dimensões contextuais que interferem na aprendizagem, o professor João evidencia fatores que interferem na avaliação, que tem data marcada para acontecer e, por exemplo, não leva em conta as eventualidades às quais estão sujeitos alunos e professores: "Eu acho que o que poderia ser destacado nesse campo seriam situações como essas, além de situações pontuais mil, não é? Que causam paralisação... enfim, várias situações que ocorrem e que acabam incidindo no resultado dessas avaliações de uma forma ou de outra" (João - Professor de História).

Quando o governo assume os escores de rendimento como expressões fidedignas da aprendizagem dos alunos de uma escola, deixa de lado as questões abordadas pelo professor. Esquecem-se das eventualidades que interferem na realização dos testes, por exemplo. As observações do professor, que ele insiste que deveriam ser levadas em conta pela política de avaliação, vão ao encontro dos resultados de pesquisas como a de Paula, Franco e Silva (2018), que destacam os fatores 
contextuais como muito importantes na determinação da situação de alunos em atraso escolar em Minas Gerais. De acordo com os autores, "têm maiores chances de atraso alunos do sexo masculino, não brancos, que trabalham fora de casa, estudam em turmas heterogêneas e em escolas que adotam programas de redução de taxas de abandono" (PAULA; FRANCO; SILVA, 2018, p. 914).

A diretora, Cleonice, aborda uma das distorções às quais o sistema de premiação pode conduzir. Segundo ela, a vantagem da vinculação entre metas e premiação é que o profissional estará atento a um objetivo, uma meta. No entanto, "o profissional que não é tão empenhado pega carona nesse resultado. [...] Tem profissional que trabalha mais do que merece receber, outros trabalham menos do que merecem receber". Ela considera a possibilidade de se fazer esse vínculo, "mas de outra maneira". Na fala da diretora ainda se percebe que, em último caso, o diretor é quem acaba sendo responsável por fiscalizar e controlar o trabalho. Ela sugere: "Talvez um acompanhamento mais de perto da Secretaria [...]. Não deixar a fiscalização e a cobrança em cima do diretor". A diretora se refere à utilização das avaliações externas para dar um retorno à escola, por meio dos analistas da $\mathrm{SEE} / \mathrm{MG}$, visando à melhoria de fato.

Ainda após essa fala de Cleonice, é possível pensar que, se um profissional que não trabalha bem passar a trabalhar melhor, e um que sempre trabalhou bem não melhorar, o que trabalhava mal vai sobressair-se. Este vai, então, receber um prêmio não por ter melhorado (que era sua obrigação), mas por ter sido ruim antes da existência do incentivo. A diretora ainda acrescenta que o prêmio está ligado diretamente à avaliação de desempenho dos professores efetivos. "Agora com os da Lei $100\left[^{6}\right]$ e os designados, quem faz é o colegiado, mas não tem vínculo com nenhuma gratificação oficial [...]" (Cleonice - Diretora). O prêmio de produtividade é pago individualmente. Uma parte das metas se refere ao trabalho coletivo na escola, mas todo servidor público do Estado de Minas Gerais passa por uma avaliação de desempenho, individual, que também conta para o recebimento do prêmio.

A coordenadora pedagógica Jussara destaca as incoerências que percebe na vinculação das metas do Prêmio de Produtividade às metas das avaliações. Para ela, o cálculo das metas é realizado levando em conta resultados de avaliações de alunos que acabaram de chegar à escola e que, por isso, não deveriam contar

\footnotetext{
A Lei Complementar Estadual n 100/2007, de 5 de novembro de 2007 (MINAS GERAIS, 2012), efetivou sem concurso público servidores que trabalharam em 2007 sob contrato temporário. Em 2015, esgotaram-se todos os recursos à ação de inconstitucionalidade movida contra a lei (Ação $n^{\circ} 4.876$ ), e o Supremo Tribunal Federal determinou o desligamento dos mais de 57 mil funcionários efetivados inconstitucionalmente, sem concurso público.
} 
como resultado de trabalho daquela escola: "[...] entra aluno de outra escola, e isso não é contabilizado na hora de se fazer a estatística. Deveria ser feita a estatística com base naqueles alunos ali, que foram nossos desde o início, porque esses têm um resultado satisfatório. O que vem de fora não tem" (Jussara Coordenadora Pedagógica). Embora, talvez, seja um número pequeno, em relação à totalidade dos alunos, o que Jussara aponta é uma questão real. A coordenadora vê o monitoramento como algo positivo, que deu um direcionamento para o trabalho dos professores, mas duvida de que seja justa a vinculação entre metas de resultados e prêmio de produtividade e insiste que a rotatividade de alunos nas escolas tem um impacto nos cálculos desses números.

O professor Cristiano, que leciona Geografia e é vice-diretor, reflete sobre a vinculação das metas do sistema de avaliação ao prêmio de produtividade. Diante da pergunta: "Como você vê a vinculação dessas metas, no Acordo de Resultados, com o prêmio de produtividade?" O professor responde: "boa pergunta". Em seguida, destaca que, quando foi criado esse sistema de bonificação, a maioria dos professores pensava apenas no prêmio de produtividade. "Como essas metas iam ser batidas, acho que não importava." Adiciona que, no entanto, uma parte dos professores sempre teve preocupações maiores. Então, se fosse colocar o bônus numa ordem de prioridade para esses professores, "talvez ficasse lá pelo terceiro lugar". Esses pautam sua motivação para o trabalho "pela questão ética do trabalhar, por ver o aluno aprendendo, que é satisfatório também para quem pensa realmente e acredita na educação".

O professor Cristiano também demonstra preocupar-se com o fato de a avaliação de desempenho ocorrer apenas para os professores efetivos: "[...] os contratados não passam por essa avaliação. [...] Os efetivos têm uma responsabilidade teoricamente maior no que diz respeito à avaliação?" (Cristiano - Vice-diretor e professor de Geografia). A questão central na fala citada é que, se o que se espera como resultado do trabalho realizado na escola é realizado por todos, como somente alguns têm seu desempenho individual avaliado? E, se a bonificação é para incentivar a realização de um trabalho de melhor qualidade, por que aqueles que não o receberão deveriam empenhar-se? Se fosse pelo compromisso que assumiram, ao aceitarem o contrato, esse mesmo princípio não deveria ser válido para os professores efetivos? São questões que não encontram respostas no texto da política educacional mineira.

O professor Cristiano também se preocupa com a premiação daquele que pode ter melhorado sua prática apenas pelo incentivo e reflete sobre a injustiça que isso caracteriza para aquele que sempre trabalhou bem: 
Aquele que independente de prêmio ou não já tem uma motivação por trabalhar, buscar resultados mesmo, que é uma motivação intrínseca, ele já pensa... É o bom profissional, né? Não preciso de prêmio para eu mostrar competência. Isso é o que eu espero de mim mesmo e o que os meus alunos e a comunidade esperam de mim. Agora, infelizmente, todo quadro tem, toda instituição, toda repartição tem mau profissional, acaba que vira uma coisa até meio claramente bem enganosa, né? Ou seja, eu vou fazer porque está me dando isso. A partir do momento em que não me passa isso, não vou preocupar com aquilo mais. Acaba que o rendimento pode ficar até pior que estava antes (Cristiano - Vice-diretor e professor de Geografia).

Nessa fala do professor, importa destacar a noção de motivo do trabalho educativo. Surge nela a relação do professor com a comunidade escolar, dos consensos democráticos e dos compromissos políticos assumidos. O professor Cristiano traz a ideia de motivação intrínseca e explica que, quando está em sala de aula ou no exercício do trabalho educativo, é o próprio interesse na formação do educando que o motiva. O professor destaca que a motivação principal está ligada ao "que os meus alunos e a comunidade esperam de mim". Isto é, tem a ver com algum compromisso político com a própria formação humana. Cristiano demonstra em diversos momentos que a motivação salarial entra no conjunto de condições para a realização (e não como prêmio pela realização do trabalho); o que determinaria o interesse por realizar o trabalho educativo estaria ligado a um compromisso político estabelecido entre professor, aluno, escola e comunidade em geral. Essa ideia sobre a motivação do trabalho educativo pode ser tomada como uma das possíveis explicações para a discordância de alguns dos sujeitos em relação à vinculação entre metas e produtividade em educação.

A fala de Cristiano corrobora o que inferem Minhoto e Penna (2011) sobre a relação entre a remuneração como prêmio e o trabalho dos professores. Considerar outros fatores, como os apontados pelo professor Cristiano, não significa negar que recompensas monetárias possam ter papel importante no recrutamento, permanência e assiduidade na carreira docente, mas significa compreender que "recompensas monetárias não influenciam necessária e diretamente o nível de engajamento profissional" (MINHOTO; PENNA, 2011, p. 162).

No tipo específico de atividade que constitui a educação, a remuneração entra como base para a realização de um trabalho em que o trabalhador não deveria exercer sua atividade de forma forçada, apenas porque seja sua condição de sobrevivência ou porque precise atingir metas para receber um bônus, 
mas porque tenha interesse direto no produto de seu trabalho. Esse produto do trabalho do professor se evidencia na própria convivência em sociedade, que reflete a disposição, pelo aluno, da cidadania formada e da apropriação da cultura humana no processo educativo. Por um lado, essa discussão nega a bonificação baseada em metas, mesmo porque ela não é aumento real da remuneração. Por outro lado, considerar a remuneração adequada como base, como condição da liberdade para se interessar pelo produto do próprio trabalho. Isto é, a remuneração não pode ser usada como reforço positivo que vise ao condicionamento do educador, mas deve constituir-se como condição que propicia a liberdade para educar.

O professor Mauro, que leciona História, diz que é contra a vinculação dos resultados a prêmios de produtividade e destaca como razão para tal posicionamento as experiências vividas em escolas pelas quais havia passado:

Eu sou contra. [...] Não virar mercenário assim. Porque eu vi coisas em escolas, de pessoas praticamente falando: a dois [questão] é "a" [alternativa correta], a três é "d". Aí, a nota vai lá pra cima. Isso não condiz com a realidade. Então, dentro do próprio professorado que é formador de opinião, tem muita gente ilícita ali. Mudando o resultado através de... dando resposta para os alunos, as respostas mais certas. Em escola que eu fiquei que era horrível... Tive lá... o menino não sabia escrever: "O Brasil é um grande país". E aí, seis na nota [do Ideb], nota máxima (Mauro - Professor de História).

O tema abordado pelo professor é delicado, porque envolve a questão ética das escolas. Ele relaciona diretamente mecanismos como burla na aplicação dos testes à irrealidade que os índices gerados passam a representar. Esse é mais um dos motivos pelo qual os professores consideram injusta a utilização das notas para comparar escolas. Ainda segundo o professor, os destinos da formação do educando deveriam ser definidos a partir de visão política, da sociedade que se deseja; não deveriam ser mera questão técnica de domínio de determinados conhecimentos. Isso revela a necessidade de se discutir coletivamente os fins da educação e os indicadores da qualidade na escola, pois, como afirma Bondioli (2013, p. 15), "definir qualidade é uma tarefa política, um trabalho democrático". Ainda no contexto dessa tarefa política democrática a que se refere Bondioli (2013), é necessário destacar a urgência da intervenção na realidade constatada por Ferreira, Berkenbrock-Rosito e Almeida (2018, p. 1255), sobre a percepção dos alunos em relação aos indicadores de qualidade. Nos discursos dos alunos, predomina a ideia de 
que eles são "usuários/receptores de conhecimento formal" os estudantes se veem como consumidores e não como sujeitos desse processo.

Nas palavras da professora Sandra, substituta no segundo ano das séries iniciais. Quando questionada sobre a premiação do mau profissional, que passaria a trabalhar apenas mediante o incentivo, a professora analisa que esse profissional poderia continuar numa zona de conforto, por exemplo, no caso de metas coletivas: "Porque se eu tenho uma escola com uma equipe muito grande e eu tô vendo que um monte de gente tá trabalhando, eu posso falar assim: 'ah, vou continuar do mesmo jeito. Eu vou ganhar mais do mesmo jeito, tá todo mundo trabalhando"”. Para essa professora, o Estado deveria priorizar o investimento em condições materiais para a realização do trabalho educativo.

As constatações da pesquisa, ainda que especificamente relacionadas à natureza do trabalho educativo, vão ao encontro das principais críticas às políticas de monitoramento da qualidade da educação, como ao treinamento de alunos para a realização dos testes; ranqueamento de instituições escolares; eliminação de estudantes considerados mais fracos da realização do exame, maior influência das notas de Matemática do que das de Língua Portuguesa no cálculo do Ideb; diferença entre o conceito de nota utilizado pelo Ideb e as notas utilizadas nas avaliações escolares; desconsideração dos contextos em que as escolas se inserem, sintetizados por Figueiredo et al. (2018).

\section{Considerações finais}

O Programa Acordo de Resultados traduz a principal ideia do monitoramento da qualidade da educação que vem sendo realizado no Brasil: transformar escores de rendimento em avaliações de larga escala em metas quantitativas para execução pelas escolas. Há na política a concepção de escores de rendimento em testes, como verdadeiros produtos da educação e das escolas como franquias que devem entregar esse produto.

O esforço da pesquisa aqui apresentada foi o de analisar a política educacional a partir da prática na escola. Os posicionamentos dos professores permitem questionar diversos aspectos dessa política: a desconsideração dos contextos em que as escolas se inserem; e a desconsideração de que vários dos fatores ligados ao rendimento escolar são externos à escola. Portanto, é complexa a adoção da lógica meritocrática entre escolas que atendem públicos distintos, ainda que pertençam à mesma rede de ensino. A política desconsidera a possibilidade de os números serem fictícios, porque diversos artifícios podem ser utilizados para inflacioná-los - e aqui não se fala apenas de mecanismos de burla, mas 
principalmente do ajustamento da realidade escolar, por meio do treinamento para os testes, possibilitado pelo próprio sistema, com banco de questões.

A partir do recorte de pesquisa apresentado neste artigo, é possível questionar ainda o fato de a política não levar em conta a peculiaridade do trabalho educativo (PARO, 2003; 2010; 2011; 2015) que, por visar à formação de sujeitos, não pode prescindir do desempenho da condição de sujeito por parte do professor. Isto é, o trabalho educativo não produz o que dele se espera se o professor não puder realizar livremente seu trabalho, como um sujeito que se posiciona diante da realidade e, coletivamente, estabelece os fins dessa atividade, planejando a adequação dos meios. Com isso, esquece-se de que o salário não deve constituir-se em reforço positivo para condicionar as ações desse sujeito. A remuneração deve propiciar exatamente o contrário: a liberdade do professor em relação às necessidades econômicas, para que ele possa interessar-se de fato, livre de preocupações, pelo produto do seu trabalho, que é a própria formação humana, conforme seu compromisso político com a comunidade escolar e com a sociedade. Sem levar em conta questões como essas, pouco adianta incrementar o investimento em sistemas de avaliação, criação de metas e programas de responsabilização. 


\title{
The educative work between targets and productivity: the results agreement in Minas Gerais
}

\begin{abstract}
This article analyzes the contractualization of results in education, which subjects the educational work to a certain concept of productivity, imposing targets for the measurement of this productivity. The qualitative research was carried out in a public school of the Minas Gerais State, with fifteen professionals, among teachers, pedagogical coordinators and school director. The discussion is based on two fundamental concepts: educative work and the productivity of this work, both arising from the conception of education as the appropriation of culture, a process of human-historical formation. Thus, the results agreement is revealed as a policy that crosses the Sistema Mineiro de Avaliação e Equidade da Educação Pública (Simave), changing the way in which the school's productivity is understood, dictating forms of control of the educative work and conforming curricular practices.
\end{abstract}

Keywords: Quality of education. Evaluation. Results Agreement.

\section{El trabajo educativo entre metas y productividad: el acuerdo de resultados en Minas Gerais}

\section{Resumen}

En este artículo, se analiza la contractualización de resultados en la educación, que somete el trabajo educativo a determinado concepto de productividad, imponiendo metas para la medición de esa productividad. La investigación cualitativa fue realizada en escuela pública de la red estadual, con 15 profesionales, entre profesores, coordinadores pedagógicos y director escolar. La discusión se basa en dos conceptos fundamentales: el de trabajo educativo y el de productividad del trabajo educativo, ambos derivados de la concepción de la educación como apropiación de la cultura, proceso de formación del humano-histórico. Así, se revela el Acuerdo de Resultados como política que atraviesa el Sistema Minero de Evaluación y Equidad de la Educación Pública (Simave), cambiando el modo como se comprende la productividad de la escuela, dictando formas de control del trabajo educativo y conformando prácticas curriculares.

Palabras clave: Calidad de la educación. Evaluación. Acuerdo de Resultados. 


\section{Referências}

BONDIOLI, A. O projeto pedagógico da creche: a qualidade negociada.

Campinas, SP: Autores Associados, 2013.

DINIZ, A. Com a crise, servidor perde prêmio por produtividade. $O$ Tempo, 3 set. 2015. Disponível em: <http://www.otempo.com.br/capa/pol\%C3\%ADtica/ com-a-crise-servidor-perde-pr\%C3\%AAmio-por-produtividade-1.1102351>. Acesso em: 22 jun. 2016.

FERREIRA, S.; BERKENBROCK-ROSITO, M. M.; ALMEIDA, J. G. Teaching and researching quality indicators: a partnership with middle school students. Ensaio: Avaliação e Políticas Públicas em Educação, Rio de Janeiro, v. 26, n. 101, p. 1240-61, out./dez. 2018. https://doi.org/10.1590/s0104-40362018002601570

FIGUEIREDO, D. et al. Os cavalos também caem: tratado das inconsistências do Ideb. Ensaio: Avaliação e Políticas Públicas em Educação, Rio de Janeiro, v. 26, n. 100, p. 552-72, jul./set. 2018. https://doi.org/10.1590/s0104-403620180026001178

FREINET, C. A educação pelo trabalho. Lisboa: Presença, 1974.

FREIRE, P. Pedagogia do oprimido. 17. ed. Rio de Janeiro, RJ: Paz e Terra, 1987.

INSTITUTO AVALIAR. Programa de avaliação da aprendizagem escolar. Belo Horizonte, MG, 2015. Disponível em: <http://paae. institutoavaliar.org.br/sistema_ava_v3/default.aspx?id_objeto=1039959\&id_ pai $=323385 \&$ area $=$ atributo $>$. Acesso em: 8 jun. 2015.

LEONTIEV, A. O desenvolvimento do psiquismo. 2. ed. São Paulo, SP: Centauro, 2004.

MARX, K. O capital. Rio de Janeiro, RJ: Nova Cultural, 1996.

MINAS GERAIS. Lei $\mathrm{N}^{\circ} 17.600$, de 1 de julho de 2008. Disciplina o acordo de resultados e o prêmio por produtividade no âmbito do poder executivo e dá outras providências. Diário Oficial de Minas Gerais, 1 de jul. de 2008.

. Lei complementar $\mathrm{N}^{\mathrm{o}} 100$, de 5 de novembro de 2012. Institui a unidade de gestão previdenciária integrada, Ugeprevi, do regime próprio de previdência dos servidores públicos do Estado de Minas Gerais e do regime próprio de previdência dos militares do Estado de Minas Gerais e o conselho estadual de previdência, Ceprev, altera a lei complementar $\mathrm{N}^{\circ} 64$, de 25 de março de 2002, e dá outras providências. Diário Oficial de Minas Gerais, 5 nov. 2007. 
MINAS GERAIS. Decreto $\mathrm{N}^{\circ} 46.170$, de 27 de fevereiro de 2013b. Altera o Decreto $\mathrm{N}^{\circ} 44.873$, de 14 de agosto de 2008, que disciplina o acordo de resultados e o prêmio por produtividade no âmbito do poder executivo e dá outras providências. Diário Oficial de Minas Gerais, 1 mar. 2013.

. Secretaria de Estado da Educação. $2^{\mathrm{a}}$ etapa do acordo de Resultados: 2013c. Belo Horizonte, MG, 2013. Disponível em: <http://portal. educacao.mg.gov.br/sysadr/>. Acesso em: 22 jul. 2015.

. Secretaria de Estado da Educação. Agência de Gestão Estratégica e Inovação. Ofício circular N 2/2013, de 19 de julho de 2013a. Pactuação de metas do acordo de resultados de 2013. Portal da Educação, 20 jul. 2013. Disponível em: <http://portal.educacao.mg.gov.br/sysadr/>. Acesso em 22 jul. 2015.

MINHOTO, M. A. P.; PENNA, M. G. O. Valorização do magistério ou darwinismo profissional? Ensaio: Avaliação e Políticas Públicas em Educação, Rio de Janeiro, v. 19, n. 70, p. 149-64, jan./mar. 2011. https://doi.org/10.1590/S0104-40362011000100009

PARO, V. H. Administração escolar: introdução crítica. 17. ed. rev. ampl. São Paulo: Cortez, 2012.

. Crítica da estrutura da escola. São Paulo: Cortez, 2011.

. Diretor escolar: educador ou gerente? São Paulo, SP: Cortez, 2015.

. Educação como exercício de poder. 2. ed. São Paulo, SP:

Cortez, 2010.

. Reprovação escolar: renúncia à educação. 2. ed. São Paulo, SP:

Xamã, 2003.

PAULA, J. S.; FRANCO, A. M. P.; SILVA, J. W. Fatores relacionados ao atraso escolar no Estado de Minas Gerais. Estudos em Avaliação Educacional, São Paulo, v. 29, n. 72, p. 886-917, set./dez. 2018. https://doi.org/10.18222/eae.v29i72.4928

UNIVERSIDADE FEDERAL DE MINAS GERAIS - UFMG. Avaliação externa como instrumento da gestão educacional nos estados. Belo Horizonte, MG, 2011. 


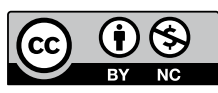

\section{Informações do autor}

Abelardo Bento Araújo: Doutor em Educação pela Universidade de São Paulo. Pedagogo do CEFET-MG. Contato: abelardo.bento@gmail.com

iD http://orcid.org/0000-0002-2441-0384 